\section{LA MUJER COMO ENCARNACIÓN DEL MAL Y LOS PROTOTIPOS FEMENINOS DE PERVERSIDAD, DE LAS ESCRITURAS AL CINE}

WOMAN AS INCARNATION OF EVIL AND FEMALE PROTOTYPES OF WICKEDNESS, FROM SCRIPTURES TO THE CINEMA

Ángeles Cruzadoa Universidad de Sevilla

Resumen:

Abstract:

Este artículo proporciona un recorrido This article provides an itinerary throughou a lo largo de la historia de la industria the history of cinematography in order cinematográfica para analizar a personajes to analyse female characters who are femeninos que destacan por su personalidad characterised by a wicked and ruthless malvada y perversa ante una sociedad personality before a patriarchal society. Many patriarcal. Se presentarán numerosos examples of femme fatale will be exposed, ejemplos de mujer fatal que han representado women who have represented wonderfully de manera magistral la maldad desde una wickedness from a wide range of roles. amplia variedad de roles.

\section{Palabras claves:}

Mujer, cine, maldad.

\section{KEY WORD:}

Woman, cinema, wickedness.
Desde la Antigüedad, numerosas han sido las figuras de mujeres destructoras, malvadas, que han usado sus encantos para seducir y, de paso, destruir a los hombres. La dualidad que identifica al hombre con el bien y a la mujer con el mal ha estado siempre presente: en la mitología grecolatina, poblada de sirenas, sibilas, brujas y hechiceras, y en la tradición judeocristiana, que en libros como el Génesis y el Apocalipsis relaciona a la mujer con la serpiente y la presenta como bestia o prostituta. "El género femenino, en los albores de la humanidad no desempeña otro papel, según testimonian múltiples pasajes, sino el de encarnar la fuerza del mal” (González Ovies, 1994: 353). A la mujer se la identifica con la astucia, la monstruosidad, la locura, y con el empleo de artimañas y trampas para llevar al hombre a la destrucción. Así, dada esta inclinación de las féminas al mal, al pecado y a la debilidad, que les impide enmendarse, surgen toda una serie de castigos y correctivos que hacen recaer sobre ellas el peso de la justicia -tanto humana como divina-, con el fin de restablecer el orden y la moral.

El imaginario patriarcal ha representado tradicionalmente a la mujer ciñéndose a la rígida dicotomía virgen-prostituta. Existía un tipo de mujer pasiva, abnegada, sometida al varón, de rasgos angelicales, y otra más orgánica, activa, fuerte y carnal, a la vez fascinante y dañina para el hombre, que alcanzaría una de sus mayores expresiones en el mito de la mujer fatal, que se desarrolla en el siglo XIX, como producto de una época de grandes cambios sociales (Dijkstra, 1994; Volpatti, 1994). Sin embargo, para hallar las raíces de este arquetipo hay que ahondar mucho más, siguiendo el rastro dejado por una gran cantidad de representaciones femeninas, a lo largo de toda la Historia del Arte y la Cultura, que nos llevarán hasta el origen mismo de nuestra tradición, allá en la Grecia clásica, fuente de la que bebe todavía hoy el imaginario colectivo de nuestra sociedad (Doane, 1991)

Como señala Carmen Ramírez, la "debilidad física, la fragilidad moral y la inmadurez ética coinciden en las distintas edades de la historia pagana y de la sagrada, para identificar a la mujer con una figura portadora del Pecado, e incluso asimilarla con el propio Mal" (Ramírez Gómez, 2002: 225). El personaje mitológico de Pandora guarda similitudes con la Eva cristiana (González Arias, 1998). Hesíodo la considera la primera mujer, que fue enviada al mundo como castigo, después que Prometeo robara el fuego del Olimpo para darlo a los hombres. Pandora poseía una impresionante belleza y una excesiva curiosidad, que la llevó a abrir la caja que le había entregado Zeus, con todos los males que azotan al mundo. El psicoanálisis identifica simbólicamente dicha caja o recipiente con la vagina (Casanova, 1979). También en Grecia, la bella Helena dejó a su marido, Menelao, para huir con Paris, hecho que originó nada menos que una guerra, cuando el esposo despechado tomó Troya para vengar la afrenta. La hermana de Helena, Clitemnestra, fue también una esposa adúltera, que mató a su marido, Agamenón, para huir con su amante Egistro. 
Sin embargo, ambas mujeres recibieron al final la muerte como castigo (Ciplijauskaité, 1984; Núñez Puente, 2001).

También asesinó a su compañero Circe, sirviéndose de uno de sus brebajes de hechicera, para reinar en solitario. Más tarde, tras su huida a Italia, se dedicó a atraer y encantar a los marineros para robarles y transformarlos en bestias. Un comportamiento similar se atribuye a las sirenas, seductoras aves con cabeza y pecho de mujer, que con sus cantos confundían a los marineros y los hacían chocar contra los arrecifes. Según Pilar Pedraza, "[l]os cantos de las sirenas están cargados de sentidos funestos, de invitaciones tanáticas, de acentos tumbales, y son, como el de la Esfinge, engaños, anzuelos mágicos que tiende la muerte a los hombres a través de un atractivo monstruo de rostro virginal y corva garra" (Pedraza, 1991: 118). Otra extraña criatura, Medusa, no destacaba por su belleza, sino por todo lo contrario. Su cabellera estaba formada por numerosas serpientes y sus ojos lograban petrificar a todo aquel que osara sostener su mirada.

Una famosa reina, Yocasta, se casó con su hijo Edipo sin conocer la verdadera identidad de éste, pues creía haberlo matado cuando era pequeño. Al conocer la realidad, lloró hasta quedarse ciega y más tarde se quitó la vida. Tampoco escatimaba en maldades Hera, esposa de Zeus. Ante las infidelidades de su marido, se mostraba celosa y vengativa con las amantes de éste y con todo aquél que no se plegara a sus deseos. A las Plétides, que decían superar su belleza, las hizo creerse vacas. Otra hechicera, Medea, tras ser rechazada por Jasón para casarse con la princesa de Corinto, se vengó provocando un incendio en el que murieron todos los habitantes del palacio real.

Existía en Grecia una divinidad, Dionisos, que es considerada por algunos como el primer dios hermafrodita, porque reúne a la vez rasgos femeninos y masculinos. Es el dios del desorden, la irracionalidad, el caos, los excesos, las orgías y borracheras, el goce, lo natural... Se trataba de un dios social, pues en sus bacanales había sitio para todos, incluidas las mujeres, que no gozaban de la condición de ciudadanas de la polis. A ellas iban destinados los ritos dionisiacos; constituían su séquito y eran sus sacerdotisas, las llamadas ménades o bacantes, mujeres semidesnudas, con el pelo suelto adornado con pámpanos, que se entregaban a la lujuria y la embriaguez en las orgías llamadas bacanales (Daraki, 2005). Lo mismo hacían brotar de la tierra surtidores de leche y miel que raptaban a niños y descuartizaban a hombres, como le sucedió, por ejemplo, a Orfeo. Pero si hay un ejemplo de feminidad perversa especialmente llamativo en la mitología griega, ése corresponde a las Amazonas (Alfonso del Real, 1967) Descendientes de Ares, dios de la guerra, eran un pueblo de cazadoras y guerreras, hasta el punto de quemar su seno derecho para utilizar mejor el arco. Usaban a los hombres sólo en cortos periodos, con el fin de procrear, y conservaban únicamente a las hijas, a las que les imponían matar a un enemigo antes de casarse. Si nacían hijos varones, les quitaban la vida o los mutilaban. Aparte de cubrir sus necesidades reproductivas, los hombres sólo podían permanecer a su lado como siervos. A pesar de su potencial guerrero, fueron derrotadas por los atenienses, pues -como se puede notar hasta ahora- toda figura femenina perversa merecía un castigo. Para Fernand Comte, "poco importa que haya existido realmente ese pueblo de mujeres y que haya realizado esos grandes hechos. Representa el sentimiento de culpabilidad de una sociedad masculina, el miedo de una separación irremediable de sexo y / o de una sumisión de los hombres a las mujeres" (Comte, 1992: 124). Jorge David Fernández (2001) sitúa en el temor de los hombres hacia las mujeres la causa del gran menosprecio con que éstas son tratadas por la mitología, que las presenta como seres terroríficos, hecho que contrasta con la situación real de discriminación que soportaban las mujeres griegas. El cristianismo, como hemos avanzado, noha sido mucho más benévoloen el tratamiento de la feminidad. La Biblia está plagada de mujeres que se ajustan perfectamente al prototipo negativo al que nos estamos refiriendo. Eva, la primera fémina creada por Dios según las Escrituras cristianas, fue seducida por la serpiente, pecó al coger la manzana del árbol prohibido y arrastró con ella a Adán. Como castigo, ambos fueron expulsados del Paraíso por un enfurecido Yahveh, que condenó a la serpiente a reptar y comerse el polvo el resto de su vida, auguró a la mujer partos dolorosos y condenó el hombre a ganarse el pan con su sudor. Sin embargo, la culpa recayó sobre Eva, quien la transmitiría a todas sus descendientes. Así lo afirmaba San Jerónimo, uno de los padres de la Iglesia: “La mujer es la puerta del Diablo, la senda de la iniquidad, la picadura de la serpiente, en una palabra, un objeto peligroso" (San Jerónimo, cit. en Bosch, Ferrer y Gili, 1999: 9). Ésta será la base de la Iglesia para considerar malas a todas las mujeres y para predicar su necesaria sujeción al varón, pues si bien el hombre puede incurrir en otros pecados, la mujer es la única capaz de tentar, y la tentación pertenece al Diablo. Ésta es la versión oficial, con la que se pone fin al culto de la Gran Madre para dar paso a largos milenios de represión femenina.

No obstante, la presencia de Eva parece muy anterior al establecimiento del judaísmo. Eva era el nombre de la Gran Diosa Madre mesopotámica y los judíos aún lo hallan escondido tras el nombre de YAHVEH: YHMH procede de la raíz hebrea HWH y significa tanto 'vida' como 'mujer'; en caracteres latinos es $E-V$-E. Con la adición de una I, formaba la invocación del nombre de la Diosa como Palabra de Creación, lo cual había sido una idea común en Egipto y en otras regiones donde la Diosa Madre estaba presente. En el gnosticismo el papel creador no corresponde a Dios sino a Eva, que hizo a Adán de sangre y arcilla; esto es, la Madre Tierra dio vida al hombre. La versión que relata el nacimiento de Eva a partir de una costilla de Adán sólo sería una transgresión patriarcal del mito de la Diosa Tierra de la que nace el héroe, que vuelve a ella cíclicamente para renacer de nuevo (Dini, 1995). Este mito es anterior al cristianismo, que deriva de él. 
Adán y Eva han nacido de la Madre Tierra, a la que regresaran. Según apunta Manuela Dunn Mascetti, en el texto bíblico que relata la expulsión del paraíso existen pruebas de que Yahveh Dios era sólo una manifestación del poder creador de la serpiente (Dunn Mascetti, 1998: 171), símbolo tomado de otras mitologías, en las que se convertía en esposo de la Madre Tierra y juntos engendraban a todos los mortales (Banc, 1945).

El cristianismo privó a Eva de su poder creador y la convirtió en un simple vientre para dar a luz a nuevos seres con dolor. El patriarcado la hizo portadora sólo de la muerte y concedió el poder de resucitar a un nuevo dios masculino. Así, el doble poder de la diosa terminó dividido: la Iglesia relacionó a Eva con la muerte y el pecado, por lo que todo el género femenino quedó maldito. Al Dios cristiano correspondió la parte buena, la de traer la salvación al mundo. Así se favoreció la actitud misógina o de desprecio hacia las mujeres en todos los ámbitos de la vida, por parte no sólo de los hombres, sino también de las propias afectadas.

Sin embargo, según las tradiciones judías, no fue Eva, sino Lilith -adaptación del demonio babilónico Lilit o Lilu-, la primera mujer creada por Dios (Bornay, 1996). Si Eva es la pecadora, Lilith -mezcla de mujer y serpiente- puede considerarse la perfecta encarnación del Diablo. La tradición judía cuenta cómo Dios la modeló exactamente igual que a Adán, sólo que, en lugar de polvo, había utilizado suciedad y heces. Lilith pronto se rebeló, e incluso se atrevió a demandar la igualdad entre sexos, al negarse a colocarse debajo de Adán durante el coito. No se dejó forzar y desapareció, libre, en el aire. "Su historia parece encarnar los más profundos temores masculinos sobre la impotencia, la debilidad y muy especialmente sobre la 'desenfrenada' sexualidad femenina, su afirmación y su independencia” (Bosch, Ferrer y Gili, 1999: 14). Lilith escapó al castigo divino, convirtiéndose así en la pionera de una "estirpe de diablesas" que logró sobrevivir. De este modo, rameras, diablesas y mujeres antinaturalmente rebeldes son la misma cosa, pues Lilith fue realmente el primer ejemplo de esa horrible criatura que más tarde se llamará mujer "emancipada" (Bornay, 1990).

Fue la primera, pero no fue la última en causar problemas a los hombres. Betsabé impactó con su belleza al rey David, que por ella cometió adulterio y mandó matar a su marido. Para liberar a su pueblo, cercado por los asirios, sedujo Judith a Holofernes y luego lo degolló. Dalila utilizó sus encantos para reducir a Sansón, al que cortó el cabello, origen de su fuerza. Otra mujer fascinante, Salomé, desplegó todo su erotismo mientras ejecutaba la danza de los siete velos y así convenció a Herodes para que matara a Juan el Bautista. También en el Nuevo Testamento, aparte de la Virgen María, destaca por su protagonismo la figura de María Magdalena, prostituta y prototipo de pecadora. Sin embargo, en los últimos años, este personaje ha sido objeto de una revisión, y hay quienes la designan como la compañera de Jesús y heredera de su legado (Grahm Brock, 2003; Gómez Acebo, 2007; Bernabé Urbieta, 1994).
Desde Lilith en adelante, la Iglesia no cesó de condenar a las mujeres diabólicas, que osaron disponer libremente de su sexualidad y alcanzar la independencia respecto a los varones. El Dios del Antiguo Testamento decretó: "A la hechicera no la dejarás con vida". Sin embargo, los primeros cristianos no se lanzaron a la caza de brujas; es más, Carlomagno, en el 800, condenaba a muerte a quien matase a cualquier persona por brujería; en el siglo XII el papa Gregorio IX prohibía a la Inquisición perseguir a las hechiceras y durante la época medieval la Iglesia declaraba que quien afirmase haber visto brujas volando sufría alucinaciones. Fue a finales del siglo XIV cuando la Europa cristiana empezó a verse invadida por una auténtica plaga de brujas, que se convirtieron en objeto de persecución y tortura por parte de los inquisidores. En 1648 la Iglesia declaró la brujería crimen exceptum, por lo que se permitiría torturar a las acusadas antes del juicio. Pocos años más tarde, el papa Inocencio VIII mandó a la Santa Inquisición perseguir a las brujas, para lo que sería de gran utilidad la obra Malleus Maleficarum (El martillo de las brujas), escrita en 1487 por los monjes dominicos Jakob Sprenger y Heinrich Kramer, que tuvo una rápida difusión gracias a la imprenta y se convirtió en el manual de los inquisidores. "Vinculadas con la danza, la noche, la naturaleza, la luna, la sexualidad y la procreación, las brujas poseían todos los atributos que previamente se le reconocían a la diosa" (Shlain, 2000: 472-473). Las víctimas de la caza de brujas fueron en su inmensa mayoría mujeres, a las que se les atribuían vuelos nocturnos, la capacidad de convertir en animales a los humanos, etc. Solía tratarse de solteras o viudas de avanzada edad, no sometidas a hombre alguno, de escasos recursos económicos, y a veces excéntricas. Sus confesiones forzadas subrayan especialmente las relaciones sexuales de las brujas con el Demonio, las orgías obscenas, los bestialismos, aunque la realidad de esas mujeres distaba mucho de las narraciones de sus perseguidores. Se trataba por lo general de sanadoras o mujeres con influencia en sus comunidades, mujeres "incómodas" y con una vida y unas ideas propias (Ehrenreich, 1988).

El hecho de que fueran casi siempre féminas las acusadas de brujería se explica por su pretendida alianza con el Demonio, de quien se suponen intermediarias, por lo que constituyen una importante amenaza para los hombres, a los que se les recomienda evitar el contacto físico con ellas, que podía acarrearles consecuencias nefastas, como enfermedades venéreas, esterilidad, impotencia e incluso la castración (Grigulévich, 2001; Donovan, 1985). La supuesta inferioridad física y mental de las mujeres las hace más susceptibles de sufrir la influencia del Demonio. A ello hay que unir su escasa memoria y su falta de disciplina, que las lleva a dejar de lado el deber. Sin embargo, la maldad natural femenina brota sobre todo de su lujuria insaciable, de su carnalidad, de su imperfección, pues la mujer está hecha de la costilla de Adán. Es engañosa, malévola, peligrosa, como una trampa, diabólica, según se afirma en el Malleus Maleficarum. 
Las que se consideraban a sí mismas brujas creian tener poderes mágicos, que empleaban fundamentalmente para realizar conjuros sobre temas amorosos. Sin embargo, a estas mujeres se les atribuía también la capacidad de realizar otro tipo de actos, inducidas por el Diablo. Además, se condenó por brujería a curanderas, parteras, mujeres con conocimientos de medicina natural o incluso simplemente con una forma de vida no demasiado ortodoxa, lo que algunos autores atribuyen a un intento de la incipiente comunidad científica y de la Iglesia de terminar con la autoridad y la fe del pueblo en esas mujeres, para fortalecer su propia posición. Hoy en día los supuestos poderes atribuidos a las brujas pueden explicarse por el empleo de estupefacientes, que podrían estar en el origen de experiencias como la sensación de volar, o por ciertas patologías o trastornos histéricos, epilépticos o alucinatorios. Sin embargo, el temor y la escasa cultura de la población favorecieron la propagación de falsas ideas acerca de la brujería, lo que dio lugar a la persecución de esas mujeres por parte de la Inquisición, ante la convicción de que rendían culto al Diablo. La Santa Inquisición, fundada por el Papa Inocencio III en 1199, hizo las veces de verdugo e instauró así un clima de terror en el que era obligatorio delatar a las culpables, so pena de correr la misma suerte que ellas.

En toda Europa se realizaron ejecuciones masivas de brujas. En Italia, entre otras muchas, destacan por su crueldad las de Brescia, donde en 1510 se dio muerte a 140 mujeres acusadas de brujería, y Como, donde murieron unas 300 en 1514. También hubo grandes juicios en ciudades como Berna, Toulouse y Heidelberg, donde ardieron las hogueras, o en North Berwick y Aberdeen, ciudades en las que se prefirió el empleo de la horca. La caza continuó en los siglos sucesivos. En Ellwangen (Alemania) fueron quemadas casi 400 brujas entre 1611 y 1618. En Nüremberg se llegó al colmo de la crueldad, al permitirse también la tortura de mujeres embarazadas y niñas, por ser consideradas herederas potenciales de las artes brujeriles de sus madres. La última ejecución oficial de una bruja tuvo lugar en Polonia en 1782. En el clima de terror que se instauró durante la época de la caza de brujas, "[l]a ancestral sabiduría femenina -en la medicina y en otros campos- acumulada con gran esfuerzo durante siglos ardió junto con las brujas" (Shlain, 2000: 482).

A partir del XIX, como consecuencia de la Revolución Industrial y de las primeras reivindicaciones feministas, la misoginia alcanza cotas elevadas en todas las manifestaciones artísticas. El progreso, la modernización y la urbanización son causas de ansiedad para el sujeto moderno. En las últimas décadas del siglo, el acceso de las mujeres a la esfera pública, con el consiguiente alejamiento del modelo de feminidad ideal, representada por el 'ángel del hogar', supondrá una nueva amenaza para los varones, que ven así peligrar su posición de privilegio social. Se sigue aconsejando a los hombres estar alerta ante la tentación que suponen los atractivos del sexo. El dominio masculino ya no se ejerce mediante la fuerza física, sino en el terreno económico. Por ello, el mayor peligro está personificado por la "mujer fatal" y sus variantes, que puede inducir al hombre a cubrirla de joyas y lujos, llevándolo así a la ruina.

Se recomienda al varón contrarrestar el contacto con las mujeres mediante el ejercicio de otras actividades que refuercen su masculinidad, como puede ser la caza. Mientras a la potencia masculina se le supone un límite, a la mujer se la imagina dotada de un apetito sexual insaciable, capaz de agotar al hombre. Surgen así una serie de tabúes destinados a aplacar ese instinto sexual femenino destructor, que amenaza con desestabilizar -mediante la astucia y la manipulaciónlos pactos establecidos entre los varones, al provocar el enfrentamiento de unos hombres con otros. Como señala Figes, es curioso que los hombres se quejen de que las mujeres intenten todo el tiempo llevarlos a la cama, " ¿Y qué otras cosas se supone que puede[n] hacer la[s] pobre[s] para no morir de tedio?" (Figes, 1972: 51) La mujer fatal en literatura o en el arte, se representa una y otra vez "como fuerza ciega de la Naturaleza, realidad seductora pero indiferenciada, ninfa insaciable, virgen equívoca, prostituta que vampiriza a los hombres, belleza reptiliana, primitiva y fatal" (Puleo, 1997: 170). Bram Dijkstra (1994) atribuye esa proliferación de imágenes femeninas perversas en el arte de finales del XIX a la mezcla de excitación sexual y miedo que suscita esa nueva mujer (Romero de Solís, 1997: 165). En esa época, el sujeto masculino occidental se ve amenazado por las razas y clases consideradas inferiores, entre ellas las mujeres, que, por su vinculación con la naturaleza, suponen un peligro para la civilización. Así, el clasismo, el racismo y el sexismo atribuyen a los individuos oprimidos los mismos rasgos de bestialidad y sexualidad agresiva, en un intento de mantener su posición de dominio y superioridad.

La razón, escribe Giuseppe Scaraffia (1987), transforma la realidad en monstruos y, como consecuencia de las ansiedades y temores masculinos, debidos a la diferencia sexual, se llega a una excesiva mitificación del cuerpo femenino (Rivera Garretas, 1996). Además, en esa época están en boga las teorías de Freud, que ayudan a justificar el sentimiento de angustia ante la mujer, por el peligro de castración que ésta supone para el hombre. Con el fin de someterla y neutralizar así la amenaza, es necesario controlar la sexualidad femenina. Se impone, por tanto, un prototipo de mujer piadosa, pasiva y sumisa, de rasgos angelicales, confinada en la esfera del hogar y la maternidad. El modelo contrario, el de la mujer orgánica, activa y sensual, que disfruta de los placeres del sexo, se considera muy negativo. No hay que olvidar, sin embargo, que la doble moral de la época llevaba a los hombres a casarse con mujeres del primer tipo, por exigencias sociales, aunque luego acudían a las del segundo para satisfacer sus deseos más carnales. En el siglo XIX, los pintores prerrafaelistas se hicieron eco de esta dicotomía, mostrando una especial fascinación por la mujer fatal, a la que representaban 
con una belleza turbia, perversa, sensual y organica, destructiva para el hombre recuperaron historias mitológicas y bíblicas para representar, por ejemplo, a Eva. Se trataba de mujeres activas, vigorosas, fuertes y sexualizadas, que surgían en parte como respuesta a la amenaza que suponía el incipiente -y marginal- feminismo de la época. Otros pintores, como Toulouse Lautrec, Manet con su Olympia, Edward Münch con su mujer vampiro o Gustav Klimt, representaron a inolvidables prostitutas y mujeres sensualmente destructivas para el hombre (Doane, 1981) En la literatura del XVIII y primera mitad del XIX se encuentran ya, según señala Scaraffia, imágenes precursoras de la mujer fatal, como Las diabólicas (D'Aurevilly, 1873); Manon Lescaut (Histoire de Manon Lescaut et du Chevalier Des Grieux, Abbé Prévost, 1885), cortesana de ojos negros; la Marquesa de Merteuil (Las amistades peligrosas, Choderlos de Laclos, 1782), que usa a su ex amante como ejecutor de sus maldades; Charpillon, capaz de jugar con el mismo Casanova (Memorias, 1790-1798); o la Cleopatra (One of Cleopatra's Nights) de Gautier, que ofrece a sus amantes una noche de amor para luego provocarles la muerte (Cfr. Ramírez Gómez, 2002). No se queda atrás la Carmen (1845) de Mérimée, perdición del soldado que por ella se hace contrabandista y termina asesinándola, despechado, por sus infidelidades. La historia de Salomé ha servido a Wilde (1893), Huysmans (À Rebours, 1884) y Flaubert (Herodías, 1877) como inspiración de sus novelas, aunque quizás una de las más perversas sea Lulú, la protagonista de La caja de Pandora (1902). El personaje creado por Wedekind destaca por su monstruosidad; sin conciencia ni remordimientos, seduce y siembra la muerte a su paso. El que la posee encuentra su perdición, y ella no se libra del merecidísimo y mortal castigo. Tras rodearse de lujo gracias a sus 'protectores', acaba prostituyéndose y muere asesinada. En 1928, una primera adaptación cinematográfica del clásico correría a cargo de G. W. Pabst, bajo el título de Die Büchse der Pandora ( $L a$ caja de Pandora). Su actriz protagonista, Louise Brooks, se caracteriza por su erotismo y su gran poder de fascinación. La película no está exenta de pinceladas lésbicas.

Las fatales decimonónicas normalmente se caracterizan por su rostro ambivalente, que les permite mostrarse como ángeles o demonios, según las ocasiones. Provocan sentimientos de amor y odio al mismo tiempo. Su seducción puede alcanzar tintes hipnóticos y privar a la víctima de toda razón. Su mirada es fascinante, seductora y asesina, como la de Medusa, hace sucumbir al hombre. Las hay con rasgos infantiles, como la Eva (1873) de Giovanni Verga. Emplean la seducción como un juego, en el que el hombre debe seguir las reglas que ellas marcan. El cabello suelto es un elemento transgresor y seductor; su belleza es imperfecta y a veces tiene algo de andrógino, como la pelusilla sobre el labio superior; esto aterroriza a los hombres, que fetichizan el cuerpo femenino en busca de algún tipo de alivio. Otros encantos de esta fémina son sus movimientos felinos y sus curvas sinuosas, envueltas en pieles, encajes y transparencias, maquilladas y perfumadas, artificiales y misteriosas.
Sin embargo, su estética no siempre resulta de buen gusto, pues más bien son una imitación vulgar de un modelo más refinado. Eso sí, muestran su cuerpo sin pudor, se ofrecen como mercancía, como bailarinas o prostitutas. A pesar de su disponibilidad, se entregan cada vez como si fuese la primera, envueltas en un halo de inocencia y castidad. No en vano la ambigüedad es uno de sus rasgos más característicos; la mujer fatal es generosa y pérfida, fácil y a la vez inalcanzable; sólo la posee el que se convierte en su esclavo. A pesar de su apariencia frígida, ofrece un placer infinito. Su posición es la de total dominadora; es ella la que elige y lleva las riendas de la relación. Cuando el enamorado se le declara, la fatal ya conocía sus sentimientos desde hace tiempo, por lo que se muestra indiferente. Una vez rota la relación, ella vuelve a atraer al amante, para seguir jugando con él. Los hombres se convierten así en "frágiles marionetas", en "víctimas", pusilánimes y sin carácter, figuras masculinas que abundan en la literatura de principios del siglo XX (Alonge, 2005).

Precisamente en ese fin de siglo, también como consecuencia del progreso industrial surge un nuevo tipo de arte, el cine, que en sus comienzos bebió hasta la saciedad de las fuentes literarias y pictóricas. El arquetipo de la mujer fatal no tardó en ser absorbido por este nuevo medio, que se convirtió en un terreno más que propicio para su desarrollo y amplificación, y a ello contribuyó especialmente el culto al star system (Paolella, 1967). En sus primeros años de vida, cohibido por su moral puritana, Hollywood se resistió a introducir figuras de mujeres seductoras y perversas, y optó más bien por reivindicar el arquetipo contrario, el de la ingenua inocente y frágil, encarnada por actrices como Lilian Gish. Fue en el viejo continente donde en las primeras décadas del siglo XX empezaron a surgir imágenes de mujeres frías, escandalosas, devora-hombres, y fuertemente seductoras. Heredera de las destructivas féminas pintadas por Münch o Klimt, el cine danés introdujo la figura de la vamp, que "juega, no goza. Su seducción es perversa y su frialdad encandila y esclaviza al espectador". Se trata de una "mujerobjeto hecha para el placer [...] cuyas características primordiales son el impulso destructivo de sed de violencia y poder, además de provocar un desencadenamiento fatídico" (Díaz Mateos y Mojarro Zambrano, 1998: 146). Una de las primeras fue Asta Nielsen, la protagonista de Hacia el abismo(Urban Gad, 1910). El cine italiano, por su parte, presenta a la vamp latina, la gran prostituta mediterránea, adornada con joyas y plumas cual odalisca, lasciva y dominadora. En el país transalpino destacan las grandes divas como Lydia Borelli o Fracesca Bertini, protagonista de Serpé (Roberto Roberti, 1919). Convertidas en figuras míticas, llevaron a la ruina o al suicidio a muchos de sus admiradores (Brunetta, 1979).

El cine norteamericano no tuvo más opción que rendirse ante la gran popularidad de estas vampiresas y acabó importando el estereotipo (Alsina Thevenet, 1993). Son mujeres de una sexualidad oscura y a veces ambigua que, aunque no chupan 
literalmente la sangre a sus víctimas, sí que los explotan sexual y económicamente hasta convertirlos en una sombra de sí mismos. La primera vamp norteamericana fue Alice Hollister, en 1913. Theda Bara, una de las más admiradas en Hollywood, fue publicitada como "la mujer más perversa del mundo". Su nombre artístico, anagrama de Arab Death (muerte árabe), fue escogido por la Fox, el estudio que la llevó a la fama y la convirtió en la primera estrella prefabricada por la industria, al teñirle el pelo de negro, restar unos cuantos años de su pasaporte e inventarle una biografía llena de misterio y exotismo: se suponía que había nacido en el Sahara, hija de un artista francés y su concubina egipcia, algo que se alejaba bastante de la prosaica realidad. En la gran pantalla dio vida a mujeres tan fatales como Carmen (Raoul Walsh 1915), Salomé (J. Gordon Edwards, 1918) o Cleopatra (J. Gordon Edwards, 1917). Mae West representó a la vamp cómica y Jean Harlow, provocativa, desenvuelta y de busto exuberante, se convirtió en la primera heroína moderna. Del otro lado del Atlántico llegarían Greta Garbo y Marlene Dietrich. La primera representa a un tipo de mujer inaccesible, miseriosa y sensual. La segunda, lanzada por Josef von Sternberg con El ángel azul (1930), pronto se convertiría en la personificación del deseo.

A partir de los años treinta, existen dos géneros dentro del cine clásico que privilegian la aparición de este tipo de féminas oscuras, tentadoras y destructivas para el hombre: el negro y el de terror (Silver y Ursini, 2004). La mujer fatal o vampiresa encaja perfectamente en el primero, que vivió su periodo más fructífero entre los años 30 y 50, y que nos ha dejado imágenes difíciles de borrar de nuestras retinas, como la de Gilda (Gilda, Charles Vidor, 1946) quitándose su guante. El cine negro surge como reflejo de los conflictos del siglo XX, marcado por los vaivenes de la economía, la violencia y la lucha por el poder. Este género tiene su germen en el periodo de entreguerras, en una época de crisis social y económica, corrupción injusticia, frustración, caos y misoginia (Guerif, 1988). La ley seca impuesta en los años 20 favoreció el enriquecimiento de la mafia, a la vez admirada y temida. Con el crack del 29, lejos de hundirse, ésta se hizo aún más fuerte y amplió su campo de acción al mundo de las drogas. El ciudadano medio se sentía indefenso y amenazado por ese incremento del crimen organizado y por la corrupción de los políticos; ante este panorama, la violación de la ley se presentaba a veces como la mejor alternativa. El cine negro, con su estética de luces y sombras, con su atmósfera opresiva y sus decorados claustrofóbicos, encarna perfectamente el espíritu de esa época en que el individuo ante la falta de puntos de referencia moral a los que aferrarse, angustiado, ve surgir el lado más oscuro de la naturaleza humana.

En cuanto a la situación de la mujer estadounidense, la discriminación es la nota dominante en los años 30. A pesar de su tímido acercamiento a la esfera política, en el mundo laboral seguía estando limitada; sólo podía ejercer ciertos trabajos y su sueldo era menor que el de los hombres. A la altísima tasa de desempleo había que sumar la actitud del Gobierno, que promovía medidas a favor del empleo masculino y en detrimento del femenino. Crecía además la xenofobia ante la oleada de inmigrantes, sobre todo italianas, que querían imitar en todo lo posible a las norteamericanas. En este clima de crisis, floreció la prostitución encubierta en burdeles y cabarets. La Segunda Guerra Mundial trajo a los Estados Unidos una época de prosperidad económica, junto a la afirmación del país como primera potencia mundial. La URSS pasó a ser la principal amenaza durante la Guerra Fría. Las vacantes dejadas por los soldados americanos durante la contienda fueron cubiertas por las mujeres, que se incorporaron al trabajo en todas las áreas. Sin embargo, tras la vuelta a la normalidad se las forzó a retomar su papel como madres y esposas, entendido éste como la única forma posible de alcanzar la felicidad. A pesar de la ola de antifeminismo que invadió el mundo laboral, las mujeres ganaron un poco de independencia aunque fuera en el vestuario, que empezó a ser más cómodo y funcional, con una tendencia masculinizadora.

El cine negro de esa década se vio marcado por el Código Hays que, en su intento por defender la moral, propició la ambigüedad; se incrementaron la fatalidad y la criminalidad femeninas, así como sus ansias de venganza, vicio y erotismo (Fernández Heredero, 1996). Muchas actrices lograron el éxito internacional gracias a este tipo de papeles, como Joan Crawford, por Rain (Lewis Milestone, 1932), o Heddy Lamarr por Éxtasis (Gustav Machatỳ, 1933). Según Roberto Campari (1990), la guerra propició la aparición de mujeres más diabólicas, que se presentaban a los hombres como un mal sueño de los soldados que volvían del frente. Durante la Segunda Guerra Mundial las vidas de muchos americanos sufrieron un vuelco tremendo, que debilitó su masculinidad, mientras las mujeres comenzaron a cuestionar las barreras tradicionalmente impuestas por los muros del hogar y empezaron a perseguir el bien material, intensificando aún más la amenaza que representaban para los hombres. Se introdujo además la psicología como elemento importante en los filmes, que se poblaron de psicópatas, cleptómanas, fobias, manías persecutorias y fatales chifladas o enfermas mentales. En los 50, una vez superadas las heridas de la guerra, los Estados Unidos lideraban el mundo, con la seguridad que les proporcionaban el crecimiento económico y el desarrollo tecnológico. De nuevo hay mujeres que buscan un trabajo fuera de casa, para satisfacer su ansia consumista, aunque el mensaje oficial sigue presionando para mantenerlas en el hogar, donde -aseguran- hallarán su felicidad. En el plano sexual hay una mayor tolerancia y apertura -aumentan las relaciones extra-conyugales-, y un intento por incluir los valores femeninos en la cultura patriarcal. Aparecen, sin embargo, nuevas figuras femeninas consideradas negativas o amenazadoras, como la universitaria y la mujer sola. En esa época de ruptura de la familia y los valores tradicionales, la cultura patriarcal deja a la mujer al margen, la oprime para suavizar la amenaza que ésta plantea al dominio masculino del mundo. 
Toda muestra de independencia femenina se considera peligrosa; para dar fe de ello, el cine negro presenta a mujeres depravadas, mentirosas, asesinas, sexualmente activas, que deben ser eliminadas para evitar así la destrucción del hombre (Santamarina, 1999).

El género negro es la expresión de las fantasías masculinas, que tienen a la mujer como protagonista y objeto; se trata de una narrativa elaborada por y dirigida al hombre. El lenguaje del cine dominante está construido desde una óptica patriarcal que concibe a la mujer como objeto de deseo, y como tal la presenta en pantalla para ser observada y proporcionar al hombre un placer escopofílico o voyeurista. El negro es uno de los géneros en los que la diferencia sexual aparece más marcada, y el cuerpo de la mujer se exhibe claramente como espectáculo. Laura Mulvey $(1975 ; 2001)$ se refiere a la distinción que hace el cine dominante entre espectáculo, representado por la mujer, que detiene la acción del filme, y narración, desarrollada por el hombre como sujeto activo. Normalmente en el cine negro ese papel corresponde al detective o investigador, que lleva el peso de la acción y es el encargado de descifrar el enigma planteado por la mujer fatal.

A pesar de su condición de objeto sexual, el personaje femenino en el cine negro desarrolla un papel importantísimo: gobierna su propio destino, se muestra como dominadora en detrimento del papel sumiso que tradicionalmente le corresponde; usa su sexualidad para lograr sus objetivos, que normalmente tienen que ver con el poder y el dinero. Incluso decide sobre su cuerpo, como en Que el cielo la juzgue (John M. Stahl, 1945), donde la protagonista opta por abortar. La mujer fatal, por tanto, es un elemento central de la intriga, y se aleja de los típicos roles femeninos. Si algo la caracteriza -no en vano le da su nombre- es la fatalidad, la desdicha y la desventura que transmite al varón. Se presenta ante él con un aspecto cautivador. A veces, como ya sucedía en la literatura decimonónica, su apariencia angelical esconde un interior perverso que ella se encargará de mantener oculto, hasta que estime oportuno descubrirse, como ocurre en el filme Cara de ángel (1953), de Otto Preminger. En otras ocasiones, su rostro pétreo e impasible, la mirada penetrante que sale de sus ojos entornados, su larga melena, sus curvas sinuosas y sus andares felinos la presentan como un volcán de sexualidad y erotismo que arrasa por donde pisa, como Barbara Stanwyck en Perdición (Billy Wilder, 1944). Además, ellas son conscientes de ese poder y se enfundan en largos trajes de satén y lentejuelas, como muñecas de lujo, objetos de culto y de deseo, dispuestas a atrapar en sus redes a todo aquél que ose alcanzarlas con su mirada. Mary Ann Doane (1991) ve ese exceso de feminidad que caracteriza a la mujer fatal como una máscara con la que se opone al rol que tradicionalmente le ha asignado la sociedad patriarcal. Para reprimir la amenaza de castración que esta mujer supone para el hombre, el cine negro recurre al sadismo, al placer que el hombre halla en investigar para descubrir el misterio femenino y, de paso, darle su merecido castigo. Otra técnica es la de negar la castración mediante el uso de objetos fetiches o la fetichización del cuerpo femenino en su totalidad, y a ello contribuye en buena medida el culto a la star, tan extendido en la época dorada de Hollywood.

Por el carácter trasgresor del género, en el cine negro la sexualidad alcanza cotas elevadas. Flota en el ambiente, de un modo velado, sobre todo en la época del código Hays. Cualquier objeto puede ser símbolo sexual, como una pulsera en el tobillo o el bordado de un pañuelo. Sin embargo, a partir de 1946 la moral se relaja y la fatal se destapa, se desinhibe, y hace gala de su voluptuosidad. Posee una sensualidad oscura e inmoral, y está cargada de símbolos fálicos, como las pistolas o sus largas piernas. Al ser un tipo de cine eminentemente 'masculino', los hombres proyectan en él sus fantasías más profundas, sus deseos ocultos; la fatal es la mujer que, en el fondo, a todo hombre le gustaría poseer, aunque el prototipo femenino más aceptado socialmente sea otro bien distinto. Esta mujer sexual representa, además, una gran amenaza para el género masculino, pues al incorporarse masivamente al trabajo para cubrir el vacío dejado por los hombres que luchan en el frente, su emancipación comienza a verse cada vez más cercana; la mujer ocupa también durante esa época el puesto del cabeza de familia, y empieza a luchar, aunque sea de forma tímida, por sus derechos. Tenemos ejemplos de mujeres liberadas, trabajadoras, que deciden librarse de sus maridos, en $\mathrm{La}$ dama de Shanghai (Orson Welles, 1848, protagonizada por Rita Hayworth) o Callejón sin salida (John Cromwell, 1947, con Lisabeth Scott).

La protagonista femenina del cine negro se presenta, por tanto, como deseable pero a la vez fuerte y peligrosa, salvaje como una pantera; el hombre tiene que controlarla y someterla para evitar ser destruido por ella. No olvidemos que la mujer salvaje está íntimamente ligada a la maga, a la hechicera, a la mujer con poderes sobrenaturales. En el cine negro el amor es importante pero no imprescindible; cuando existe suele ser por parte del hombre y está marcado por el machismo. La familia tradicional no tiene cabida en este género, en el que las mujeres contraen matrimonio para ascender socialmente y ven el amor como un juego para manejar a los hombres. El amor implica sufrimiento y no está exento de mentiras y crueldad; a veces incluso es algo patológico, posesivo y turbulento. Según Nuria Bou, "Casarse es, para la femme fatale, una manera de despistar-de alejarse, en este caso, de un insidioso cuestionario-, de construir una nueva máscara: el hogar, para la vampiresa, es una estructura de poder, un recinto para mejor urdir nuevas estrategias y proteger sus armas" (Bou).

El sexo se trivializa y se emplea para saciar las ansias de riqueza y poder que mueven a la mujer fatal. A ésta no le importa tanto el amor como estar rodeada de lujo y joyas; la fatal goza con el dinero tanto o más que con el sexo, pues la ambición económica es para ella lo que para el hombre es la potencia sexual. 
Para lograr el ascenso social esta mujer está dispuesta a entrar en el mundo del crimen y los bajos fondos. No duda en eliminar a quien pueda ser un obstáculo para sus ambiciones. Las hay que matan al marido para quedarse con su dinero, por ejemplo en Eva al desnudo (Joseph L. Mankiewicz, 1950), o mejor aún, convencen al amante para que realice el trabajo sucio. En El cartero siempre llama dos veces (Tay Garnett, 1946), el amante de Cora (Lana Turner) mata al marido de ésta y, además, el crimen queda impune. Otras asesinan o roban por dinero o para servir al amante mafioso, pero llegado el momento lo delatan sin piedad. Chantajean, engañan, traicionan incluso a su propia familia; maltratan a la madre, le roban el amante, matan incluso al marido de la hermana. Llegan a pactar con el enemigo de su hombre, pues el amor, como ya se ha dicho, tiene un valor muy relativo en comparación con elementos más materiales. Su maldad no tiene límites; encarnan el pecado (son lujuriosas, vengativas, iracundas, avaras, soberbias...) y la depravación más absoluta. Son frías, insensibles, despiadadas, crueles, desleales. Se rebelan contra la sociedad que les impone dedicarse al cuidado de los hijos y la familia. Destruyen a los hombres pero también a cualquier mujer que ose hacerles sombra. Según María Dolores Romero Guillén, estas mujeres se caracterizan "por su poder seductor para transformar en caos el orden aparentemente existente" (Romero Guillén, 2000). Encarnan lo peor de la feminidad y poseen además cualidades masculinas (la ambición, el materialismo, el gusto por el riesgo, la libertad, los vicios, la egolatría...) que, aplicadas a la mujer, aumentan el temor que ésta suscita en el hombre, entendido como "la posibilidad masculina de perder prestigio, la libertad o la vida tras el calvario por la devoción hacia una mujer cuya fatalidad le abrirá la plenitud de los sentidos" (Belluscio, 1996: 145).

Nuria Bou destaca la importancia del imaginario marino y acuático en la configuración de la fatal cinematográfica. No son pocas las que seducen a sus víctimas junto al mar, como Lana Turner en El cartero siempre llama dos veces (Tay Garnett, 1946) o Jane Greer en Retorno al pasado (Jacques Tourneur, 1947). Otras despliegan sus cabelleras sinuosas y onduladas como un mar de aguas turbulentas, como es el caso de Coral Chandler en Callejón sin salida (John Cromwell, 1947) o Barbara Stanwyck en Perdición (Billy Wilder, 1944). Además de en las cabelleras, las ondulaciones están presentes en los cuerpos, envueltos en satenes ajustados que realzan sus curvas y sus movimientos sinuosos. La autora señala a la Marilyn Monroe de Niágara (Henry Hathaway, 1952) como la primera en dejar atrás el negro para enfundar en un vestido fucsia sus carnes onduladas. La mujer perversa del cine negro presenta distintas variantes. Por un lado está la 'chica del gánster', su mantenida, que no es más que un simple trofeo, un objeto de disputa entre los hombres, como Glenda Farrell en Hampa dorada (Mervyn LeRoy, 1931). Está sometida pero no goza con su opresor y por ello tiene que buscar el placer en otros hombres. La 'aventurera', en cambio, es más activa, y mantiene con el varón una relación de tú a tú, no se somete a él. Es su cómplice; lo defiende y también lo humilla. No tiene miedo al riesgo y desafía las normas socialmente aceptadas, cómo Ava Gardner en Forajidos (Robert Siodmak, 1946). Sólo la muerte puede redimirla. La 'lady dark' es sensual y muy inteligente. Sabe bien lo que quiere, y juega con el sexo y el amor para conseguirlo, como Mary Astor en El halcón Maltés (John Huston, 1941). También es consciente del castigo que merece: la muerte. La 'bad-good girl' o 'chica buena metida en líos' tiene un aspecto dulce e infantil y buen corazón, pero la fatalidad se apodera de ella cuando se alía con el delincuente, como le sucede a Marilyn Monroe en La jungla de asfalto (John Huston, 1950). La 'fatal' con mayúsculas es la que encarna todas las maldades, además de la seducción, el riesgo, la actividad, la inmoralidad y la destrucción. Marta Belluscio distingue, dentro de esta categoría, entre la 'adúltera asesina', la 'mala calculadora' y la 'ruin inefable'.

En estos filmes aparece también, aunque en mucha menor medida, la variante contraria, el 'ángel', la mujer buena, pasiva, sumisa y silenciosa, encerrada tras los muros del hogar, que ofrece al bandido la posibilidad de redimirse y volver al buen camino. Esta mujer es incluso capaz de dar su vida por la salvación del hombre. Hay además esposas-víctimas asesinadas por el marido para quedarse con su fortuna, hermanas incestuosas y depravadas, y madres pasivas, responsables de los delitos de sus hijos. Junto a estas mujeres desfila por las pantallas del negro toda una galería de maridos sufridores y damnificados, detectives incorruptos que sucumben ante este amor fatal, gánsteres y criminales de todo tipo, misóginos y violentos, masoquistas que roban, matan y van a la cárcel por una mujer, antihéroes de moral dudosa que se convierten en un juguete en manos de ella, víctimas todos de esa mujer araña que los atrapa en su tela, los esclaviza y los destruye. Este elenco de personajes se mueve en ambientes turbulentos, asfixiantes, como la atmósfera típica del género; frecuentan garitos, burdeles, hoteles baratos, locales de juego clandestinos, prostíbulos, comisarías y clubes nocturnos en los que la fatal desarrolla su espectáculo. Como chicas de alterne, prostitutas, busconas, coristas... acompañan su voz grave con gestos seductores y emiten cantos de sirena que atraen y a la vez siembran el caos. En una escena inolvidable, a Ava Gardner (Forajidos, Robert Siodmak, 1946) le basta con entonar una canción al piano para hipnotizar cual sirena a un Burt Lancaster que cae rendido a sus pies. Si la canción se enmarca en un espacio típicamente femenino, el de la seducción y el lamento, la danza es la "transposición del acto sexual". De hecho, hace ya siglos que permitió a Salomé ver realizados sus deseos. Cantando lo expresa todo, pero la fatal es parca en palabras; sus diálogos son rápidos e irónicos; prevalece el misterio de su naturaleza turbia y sospechosa, de su belleza inquietante y ambigua; no necesita realmente hablar mucho, pues emplea, con ostentación, su cuerpo como señuelo y ejerce una atracción fatal con cada detalle: con su voz grave, su mirada pérfida, sus escotes sugerentes, su boca entreabierta fumándose un pitillo, sus movimientos insinuantes. Hay que aludir de nuevo a Gilda (Gilda, Charles Vidor, 1946), que sólo 
se quitó un guante pero encabeza la lista de los streapteases más famosos de la historia del cine. El lenguaje fílmico juega también un papel decisivo en la construcción de esa aura que envuelve a la fatal, al filmarlas desde abajo, de modo que ellas aparecen en una posición de superioridad respecto a los hombres, filmados desde arriba. La mujer se muestra, además, centrada o en primer plano.

Según E. Ann Kaplan (1983), el patriarcado destruye a la mujer independiente, que lucha por tener un discurso y una subjetividad propia. La mujer fatal, como hemos comentado, destaca por ser no sólo objeto sino sujeto; por ello, irremediablemente, debe ser castigada para restaurar así el orden patriarcal. La mujer fatal se convierte en víctima de la violencia masculina y en la mayoría de los casos paga con su vida los pecados cometidos. Muere de todas las maneras posibles, la traición y el adulterio jamás quedan impunes. Así el hombre elimina el caos originado por la maldad femenina y restaura el orden. A las espectadoras les ha quedado claro, sin duda, el tipo de papel que deben desempeñar en la sociedad y el castigo que les espera a las que osen transgredir las leyes patriarcales. El mito de la mujer fatal en el cine vivió su época dorada entre los años 30 y 50, aunque todavía hoy sigue vivo y no ha sufrido, a pesar de los cambios experimentados por la sociedad, grandes variaciones. Desde finales de los $50 \mathrm{y}$, sobre todo, en los 70, las relaciones entre hombres y mujeres empiezan a mostrarse de un modo más directamente sexual, y la generalización del color ha terminado con esas atmósferas turbias propias del género negro en décadas anteriores. En los años 80 y 90 se introducen nuevos elementos temáticos relacionados con el mundo del crimen y la delincuencia, que actualizan las antiguas tramas de gánsteres y corrupción. Sin embargo, sigue existiendo, como afirma Marta Belluscio, "la mirada misógina hacia una hembra esculpida a la medida del deseo, el odio y la fantasía de los hombres" (Belluscio, 1996:36) Filmes como el remake de El cartero siempre llama dos veces (Bob Rafelson, 1981), con Jessica Lange, Fuego en el cuerpo(Lawrence Kasdan, 1981), o Instinto básico (Paul Verhoeven, 1992) son mucho más explícitos en el plano sexual. El principal protagonista de Fuego en el cuerpo, aparte de los personajes que constituyen el triángulo amoroso, es el miedo masculino ante la mujer liberada, desinhibida e independiente que amenaza con invertir la situación de dominación de los hombres sobre las mujeres, el temor que todavía suscita la sexualidad femenina. La protagonista de Instinto básico es la perfecta reencarnación de una mantis religiosa que devora al policía y hace que éste culpe a otra mujer de los delitos cometidos por ella misma.

En los años noventa surgen, además, películas que retoman la temática del cine negro, pero en tono de parodia, como La chica del gánster (John McNaughton, 1993) o Pulp Fiction (Quentin Tarantino, 1994), ambas protagonizadas por Uma Thurman, en una versión renovada de la chica del gánster. La primera cuenta la historia de un mafioso que, tras ser salvado por un policía, le presta a su chica durante una semana como recompensa y ambos terminan peleándose por ella. En la segunda, la actriz da vida a una cocainómana a la que su protector envía con un amigo -interpretado por John Travolta- para que la entretenga. Ya en los albores del siglo XXI, la película Moulin Rouge (Baz Luhrman, 2001) nos presenta a una mujer que se ajusta perfectamente al prototipo de fatal, según la describen Díaz Mateos y Mojarro Zambrano: “con una cabellera larga, abundante y rizada, muchas veces pelirroja, con la tez muy blanca, y un aspecto muy seductor y voluptuoso" (Díaz Mateos y Mojarro Zambrano, 1998: 145). Con un aspecto físico muy similar al que describen estos autores, embutida en un conjunto de lencería negra de encaje y cubierta por una bata transparente que deja entrever sus curvas sinuosas, se presenta Satine -encarnada por Nicole Kidman- ante el supuesto Duque, con la intención de seducirlo y acceder a sus riquezas. Estamos ante una digna heredera de la clásica mujer fatal -aunque, en este caso, de buen corazón- que maneja a los hombres a su antojo y lleva al amante, como hiciera Eurídice con Orfeo, al mundo dionisiaco del vicio y los bajos fondos de la sociedad. Si bien es cierto que demuestra ser más sensible de lo habitual y que termina enamorándose y renunciando por amor a la riqueza a la que aspiraba, esto tampoco le da derecho a salvarse. No hay reinserción posible, la única solución es la muerte.

Otro género cinematográfico que se caracteriza por contar con inquietantes presencias femeninas es el de terror, que a partir de los años treinta desarrolla una estética de la fealdad y se puebla de seres monstruosos. Éstos suelen ser, casi siempre, de origen animal o, al menos, de género masculino. De hecho, la mayoría de los autores abordan las figuras femeninas en los filmes de terror en cuanto víctimas. Sin embargo, también aparece todo un elenco de mujeres monstruosas, maléficas, con una sexualidad agresiva, que a la vez seduce y aterroriza. Son figuras activas, lo que no implica que se trate de representaciones feministas. Estas imágenes de la feminidad, lo mismo que las fatales, surgen como consecuencia del temor masculino ante los nuevos modelos de mujer que brotan a raíz de los cambios sociales que se dan en esa época. Barbara Creed (1993) hace un recorrido por las distintas formas que adopta el monstruo femenino: éste aparece como bruja (Carrie, Brian de Palma, 1976), mujer poseída (El exorcista, William Friedkin, 1973), vampira (The Hunger, Tony Scott, 1983), madre ancestral (Alien, Ridley Scott, 1979), psicópata (¿Qué fue de Baby Jane?, Robert Aldrich, 1962), belleza asesina (Instinto básico, Paul Verhoeven, 1992), animal (La mujer pantera, Jacques Tourneur, 1942), castradora (I spit on your grave, Meir Zarchi, 1978), etc. La autora, siguiendo a Julia Kristeva (1980), argumenta que en la mayoría de los casos la representación de la mujer como monstruo tiene que ver con su aspecto materna y reproductivo. Además, la concepción freudiana de la mujer como castrada ha dado lugar a la representación de féminas castradoras. 
Según Kristeva, la figuración del monstruo en los filmes de terror hunde sus raíces en el concepto religioso de lo abyecto ("despreciable, vil en extremo" según el D.R.A.E.), entendido como "inmoralidad sexual y perversión; alteración corpórea, descomposición ymuerte;sacrificiohumano; asesinato;elcadáver;residuoscorporales;elcuerpofemenino yelincesto" (Creed,1993:9). Elabyectosesitúaenunterritoriofronterizo:entrelohumano y lo animal, entre el bien y el mal, entre lo natural y lo sobrenatural; en el límite que separa los roles genéricos y el deseo sexual que se consideran normales para cada sujeto. Ya en los años del mudo podemos encontrar las primeras representaciones de mujeres monstruosas en el cine de terror. En 1922 Maren Pedersen da vida a la protagonista de Häxan, un documental sobre la historia de la brujería realizado en Dinamarca por Benjamin Christensen. Se trata de un filme repleto de brujas, monstruos y ritos satánicos, del que ha bebido toda la imaginería sobre brujas posterior. En Alemania, en 1927, Henrik Galeen dirigió Mandragora, protagonizada por Brigitte Helm. En esta película, un médico insemina a una prostituta con el semen de un delincuente para engendrar a una niña que será la encarnación del mal. En 1931, Vampyr, realizada por Carl Theodor Dreyer, se sitúa en la frontera entre el cine mudo y el sonoro para hacer una adaptación de varios relatos de Sheridan Le Fanu y cuenta la historia de una bruja vampiro, que se convierte así en la primera de toda una serie de vampiras cinematográficas.

El mito del vampiro tiene su origen en la leyenda de la condesa húngara Erzsébet Báthory (1560-1614), acusada de ejercer la brujería y de asesinar a cientos de muchachas para bañarse en su sangre y alcanzar así la eterna juventud. Bram Dijkstra (1994) apunta a una creencia de la época según la cual las mujeres se convertían en vampiros para recuperar la sangre perdida durante la menstruación. Otros autores identifican la mordedura del vampiro a una muchacha con la pérdida de su primera sangre menstrual, tras lo cual la víctima se transforma y se llena de vigor y energía.

La mordedura en el cuello es un acto íntimo y lleno de erotismo. Cuando el vampiro es masculino, no suele ir ligada a connotación homosexual alguna, pero en el caso de las vampiras, las tendencias lésbicas suelen estar casi siempre presentes, al principio de manera más velada $\mathrm{y}$, a partir de los años setenta, abiertamente, coincidiendo precisamente con el movimiento de liberación de la mujer, que hizo aumentar el miedo de los hombres ante una sexualidad femenina cada vez más agresiva. Según Creed, "[l]a de 'lesbiana' y 'vampiro' es una feliz combinación puesto que ambas figuras son representadas en la cultura popular como mujeres sexualmente agresivas" (Creed, 1993: 25).

Tras Vampyr (1931) de Dreyer, una de las primeras representaciones de la vampira la encontramos en La hija de Drácula(Lambert Hillyer, 1936), filme en que Gloria Holden da vida a la Condesa Marya Zaleska, gran aficionada a la brujería y a todo lo esotérico.
En 1960 el británico Terence Fisher dirigió Las novias de Drácula, obra mucho más explícita que las anteriores en lo sexual.

Dentro del género fantástico y de terror encontramos también otro tipo de féminas monstruosas. En 1935, James Whale da a la famosa criatura de Mary Shelley una compañera, en La novia de Frankenstein, protagonizada por Elsa Lanchester. Es creada del mismo modo que él, a partir de un cadáver, por lo que su belleza se sale de los cánones clásicos, con un cabello encrespado y electrizado y canas prematuras. En ocasiones la mujer se convierte en una fiera, como en La mujer pantera (1942), de Jacques Tourneur, en la que la belleza felina de Simone Simon sirve a esta actriz para interpretar a la perfección a una diseñadora de origen serbio que cree transformarse en pantera ante cualquier hecho que pueda encender su sexualidad. El tema fue retomado en dos secuelas, The curse of the cat people (Gunther von Fritsch y Robert Wise, 1944) y El beso de la pantera (Paul Schrader, 1981). También en los años cuarenta, destaca la trilogía protagonizada por la bella mujer-gorila Paula Dupree, creada por un científico tras transplantar a un simio glándulas femeninas. Acquanette le dio vida en las dos primeras entregas, Captive wild woman (Edward Dmytryk, 1943) y Jungle Woman (Reginald le Borg, 1944), y Vicky Lane en la tercera, Jungle Captive(Harold Young, 1945).

En los años cincuenta surge un nuevo sub-género denominado por Barbara Creed 'cinema of lost women', protagonizado por mujeres que, quizás como una recuperación de las antiguas Amazonas, desean vivir apartadas de los hombres. En Queen of Outer Space (Edward Bernds, 1955), protagonizada por Zsa Zsa Gabor, tres astronautas llegan a Venus y encuentran un planeta poblado sólo por mujeres vestidas con minifalda y tacones, y gobernadas por una reina que odia a los hombres y desea destruir la Tierra. En The She-Creature (Edward L. Cahn, 1956), Marla English da vida a la ayudante de un hipnotizador que desciende de un ancestral monstruo marino. Cuando su jefe la hipnotiza, se convierte en un ser destructivo y asesino. Por último, en Voodoo Woman (Edward L. Cahn, 1957), un científico loco quiere crear a una mujer que ejecute por él sus planes asesinos, pero la idea se le va de las manos y da vida a un monstruo al que es incapaz de controlar.

Además de éstas, siguen surgiendo otras muchas mujeres diabólicas. En 1955 HenriGeorges Clouzot dirigió Les Diaboliques, filme protagonizado por Simone Signoret en el que dos mujeres se unen para librarse de un hombre que es a la vez el marido de una y el amante de la otra, mientras que esta última se alía con él para asesinar a la primera. Dentro del cine de terror gótico italiano destaca Mario Bava, con filmes como La máscara del demonio (1960), que cuenta la leyenda de la bruja Asa, muerta en la hoguera. Su protagonista es Barbara Steele, una de las mayores estrellas del género, que destaca por expresar una perfecta conjunción entre el sexo y la muerte. La actriz, a diferencia 
de las rubias elegidas por Hitchcock como protagonistas de sus filmes, aporta una imagen inusual hasta entonces en el género: su rostro geométrico, de grandes ojos negros, y su cabello moreno le valieron para interpretar a mujeres malvadas $\mathrm{y}$, a la vez, tristes y sensibles. Las protagonistas de ¿Qué fue de Baby Jane? (Robert Aldrich, 1962) no destacan por su belleza y sensualidad, sino más bien por su fuerza, su locura y su perversidad. El filme se centra en la rivalidad entre dos hermanas: Baby Jane (Bette Davis) se consagró como estrella infantil mientras Blanche (Joan Crawford) permanecía en la sombra, pero los papeles se invirtieron. Sin embargo, esta última, tras ser misteriosamente atropellada, quedó postrada en una silla de ruedas y ambas permanecen recluidas en la misma casa, donde sus odios y rencores las someten a un enfrentamiento constante, a pesar de su mutua dependencia.

La figura materna se perfila también como monstruo en potencia. Psicosis (Alfred Hitchcock, 1960) presenta a la que Creed denomina 'madre castradora', una madre posesiva y dominante en exceso que anula a su hijo, quien se convierte, como consecuencia de ello, en un psicópata asesino. En el caso de Carrie (Brian de Palma, 1976), es el fanatismo religioso lo que lleva a la madre a destruir a su hija. En un filme más reciente, Atracción fatal (Adrian Lyne, 1987), el deseo edípico de tener un hijo y un marido conduce a su protagonista a la psicosis más extrema. Todas estas imágenes de monstruosidad femenina, lo mismo que las fatales, no son sino la expresión del miedo de los hombres ante la mujer, sobre todo en épocas en que ésta empieza a desmarcarse del rol que la sociedad patriarcal le tiene destinado. La construcción de esa feminidad monstruosa es fundamental para el mantenimiento del orden social masculino. Por tanto, la creación de un nuevo imaginario se perfila como crucial para destruir dicho orden y crear uno nuevo, en el que sí tengan cabida las necesidades y los deseos de las mujeres reales.

REFERENCIAS BIBLIOGRÁFICAS

Alfonso del Real, C., Realidad y leyenda de las amazonas, Madrid, Espasa-Calpe, 1967.

Alonge, R., Donne terrifiche e fragili maschi, Laterza, Bari, 2005.

Alsina Thevenet, H., Historia del cine americano, Barcelona, Laertes, 1993.

Banc, A. C., Il sacro presso i primitivi, Roma, Astrolabio, 1945.

Belluscio, M., Las fatales ¡Bang! ¡Bang !, Valencia, La Máscara, 1996.

Bernabé Urbieta, C., María Magdalena. Tradiciones en el cristianismo primitivo, Estella, Verbo Divino, 1994.

Bornay, E., Las hijas de Lilith, Madrid, Cátedra, 1990.

----, "Eva y Lilith: dos mitos femeninos de la religión", en Historia del arte y mujeres,

Málaga, Universidad de Málaga, 1996.
Bosch, E., Ferrer, V. A. y Gili, M., Historia de la misoginia, Barcelona, Anthropos, 1999. Bou, N., "Retrato nocturno de la femme fatale“, Formats 3.

Brunetta, G., Storia del cinema italiano, Roma, Editori Riuniti, 1979.

Campari, R., Il discorso amoroso (Melodrama e commedia nella Hollywood degli anni d'oro), Roma, Bulzoni, 1990

Casanova, A., La famiglia di Pandora. Analisi filologica dei miti di Pandora e Prometeo nella tradizione esiodea, Firenze, CLUSF, 1979.

Ciplijauskaité, B., La mujer insatisfecha. El adulterio en la novela realista, Barcelona, Edhasa, 1984.

Comte, F., Las grandes figuras mitológicas, Madrid, 1992.

Creed, B., The monstruous-feminine. Film, feminism, psychoanalysis, London, Routledge, 1993.

Dakari, M., Dioniso y la diosa tierra, Madrid, Abada editores, 2005.

Díaz Mateos, A., Díaz Mateos, V. y Mojarro Zambrano, M., “'Bésame tonto': la mujer fatal en el cine", en Cien años de cine: la fábrica de los sueños, Sevilla, Facultad de Ciencias de la Información, 1998.

Dijkstra, B., Ídolos de perversidad. La imagen de la mujer en la cultura de fin de siglo, Madrid, Debate, 1994

Dini, V., Il potere delle antiche madri, fertilità della terra, fecondità della donna e culto delle acque nella devozione magico religiosa, Florencia, 1995.

Doane, M. A., “The woman's film: possession and address", en Re-visions: Feminist Essays in Film Analysis (P. Mellencamp, L. Williams y M. A. Doane, eds.), Los Angeles, American Film Institute, 1981.

----, Femmes fatales. Feminism, film theory, London \& New York, Routledge, Chapman and Hall, 1991.

Donovan, F., Historia de la brujería, Madrid, Alianza, 1985.

Dunn Mascetti, M., Diosas. La canción de Eva, Barcelona, Robinbook, 1998.

Ehrenreich, B., Brujas, comadronas y enfermeras. Historia de las sanadoras, Barcelona Lasal, 1988.

Fernández Gómez, J. D., “La dualidad de géneros en el mito griego: el caso del Dios femenino", en Mujer, cultura y comunicación: Realidades e imaginarios, Sevilla, Alfar, 2001

Figes, E., Actitudes patriarcales: las mujeres en la sociedad, Madrid, Alianza Editorial, 1972.

Gómez Acebo, I. (ed.), María Magdalena, Bilbao, Desclée, 2007. 
González Arias, L. M., Cuerpo, mito y teoría feminista: re/visiones de Eva en autoras contemporáneas, Oviedo, KRK, 1998.

González Ovies, A., "Mito: masculino singular", en Género y sexo en el discurso artístico (Caramés y González, eds.), Oviedo, Servicio de Publicaciones de la Universidad de Oviedo, 1994.

Grahm Brock, A., Mary Magdalene the First Apostle. The Struggle for Authority, Cambridge, Harvard University Press, 2003.

Grigulévich, I., Brujas - herejes - inquisidores. Historia de la Inquisición en Europa y Latinoamérica, Ahriman International, cop. 2001.

Guerif, F., El cine negro americano, Barcelona, Martínez Roca, 1988.

Kaplan, E. A., Women and film. Both sides of the camera, London / New York, Routledge, 1983.

Kristeva, J., "Motherhood according to Bellini", en Desire in language: a semiotic approach to literature and art (Leon S. Roudiez, ed.), Nueva York, Columbia University Press, 1980.

Mulvey, L. (1975), “Visual Pleasure and Narrative Cinema”, en Visual and Other Pleasures, Bloomington e Indianapolis, Indiana University Press, 1989; trad. esp., "Placer visual y cine narrativo", en Arte después de la modernidad (Wallis, ed.), Madrid, Akal, 2001.

Núñez Puente, S., Ellas se aburren. Ennui e imagen femenina en La Regenta y la novela europea de la segunda mitad del XIX, Alicante, Universidad de Alicante, D. L., 2001.

Paolella, R., Historia del cine mudo, Buenos Aires, Editorial Universitaria de Buenos Aires, 1967.

Pedraza, P., La bella, enigma y pesadilla (Esfinge, Medusa, Pantera...), Barcelona, Tusquets, 1991.

Puleo, A., "Mujer, sexualidad y mal en la filosofía contemporánea”, Daimon (Murcia), nº 14, enero-junio 1997, pp. 167-172.

Ramírez Gómez, C., "Mujeres del mal en la literatura francesa”, en Las mujeres y el mal (Palma Ceballos y Parra Membriles, eds.), Sevilla, Padilla, 2002.

Rivera Garretas, M. M., El cuerpo indispensable. Significados del cuerpo de mujer, Madrid, Horas y horas, 1996.

Romero de Solis, D., "El miedo a la mujer (arte, sexualidad y fin de siglo)", Daimon. Revista de Filosofía de la Universidad de Murcia, no 14, enero-julio 1997.

Romero Guillén, M. D., Las mujeres en el cine americano de Fritz Lang, Zaragoza, Mira Editores, 2000.

Santamarina, A., El cine negro en 100 películas, Madrid, Alianza, 1999.

Scaraffia, G., La donna fatale, Palermo, Sellerio, 1987.

Shlain, L., El alfabeto contra la diosa. El conflicto entre la palabra y la imagen, el poder masculino y el poder femenino, Madrid, Debate, 2000.

Silver, A. \& Ursini, J., Cine negro (P. Duncan, ed.), Madrid, Taschen, 2004. Volpatti, L., Sul braccio dei colei. Breve viaggio letterario nella perfidia femminile, Milano, Baldini \& Castoldi, 1994. 